\title{
Curious Case of Peritoneal Loose Body
}

\section{Sanjay Chatterjee ${ }^{1 *}$ and Sameer Deshmukh ${ }^{2}$}

${ }^{1}$ Assistant Professor, Maharashtra University of health sciences, Maharashtra, India.

${ }^{2}$ Bombay Institute of Medical Sciences and Research Centre Maharashtra, India.

*Corresponding Author: Sanjay Chatterjee. Assistant Professor, Maharashtra University of health sciences, Maharashtra, India.

Received date: January 08, 2021; Accepted date: January 23, 2021; Published date: March 13,2021

Citation: Deshmukh S, Chatterjee S. (2021) Curious Case of Peritoneal Loose Body. J Surg. Cas Repo and Imag 4(2); DOI: 10.31579/2690-1897/055

Copyright: ( ) 2021, Sameer Deshmukh, This is an open access article distributed under the Creative Commons Attribution License, which permits unrestricted use, distribution, and reproduction in any medium, provided the original work is properly cited.

\begin{abstract}
Peritoneal loose bodies (PLB) also known as "peritoneal mice", are rare lesions often found incidentally during laparoscopies or laparotomies. They are often small in size although PLBs measuring in size more than $5 \mathrm{~cm}$ have also been reported. Most small PLBs remain asymptomatic and do not require treatment, although large PLBs have also been known to cause symptoms like urinary obstruction, intestinal obstruction. We present one such case of a middle- aged man having a PLB causing subacute intestinal obstruction.
\end{abstract}

Keywords: Peritoneal loose bodies; urinary obstruction; intestinal obstruction

\section{Case Report}

A 54 year old man presented with pain in the abdomen since 15 days. Pain was located mainly to the right iliac fossa, non-radiating dull aching type of pain with no aggravating or relieving factors. He also had complaints of post meal abdominal distension and nausea, which used to resolve by itself. On examination, his vital parameters were normal. Cardiovascular system, respiratory system and central nervous system examination was unremarkable and the abdomen was soft, with no tenderness or any palpable lump.
A Sonography of the abdomen revealed the presence of a hypoechoic space occupying lesion (SOL) in the pelvis on the right side, having well defined margins.

A Computerised Tomography (CT) scan with oral and intravenous contrast showed the presence of a hyperdense non-enhancing oval lesion with well-defined margins in the mesentery of the right iliac fossa. The lesion also showed the central fat density with peripheral rim of calcification. Based on the radiological findings, a pre-operative provisional diagnosis of an ileal mesenteric mature teratoma was given.

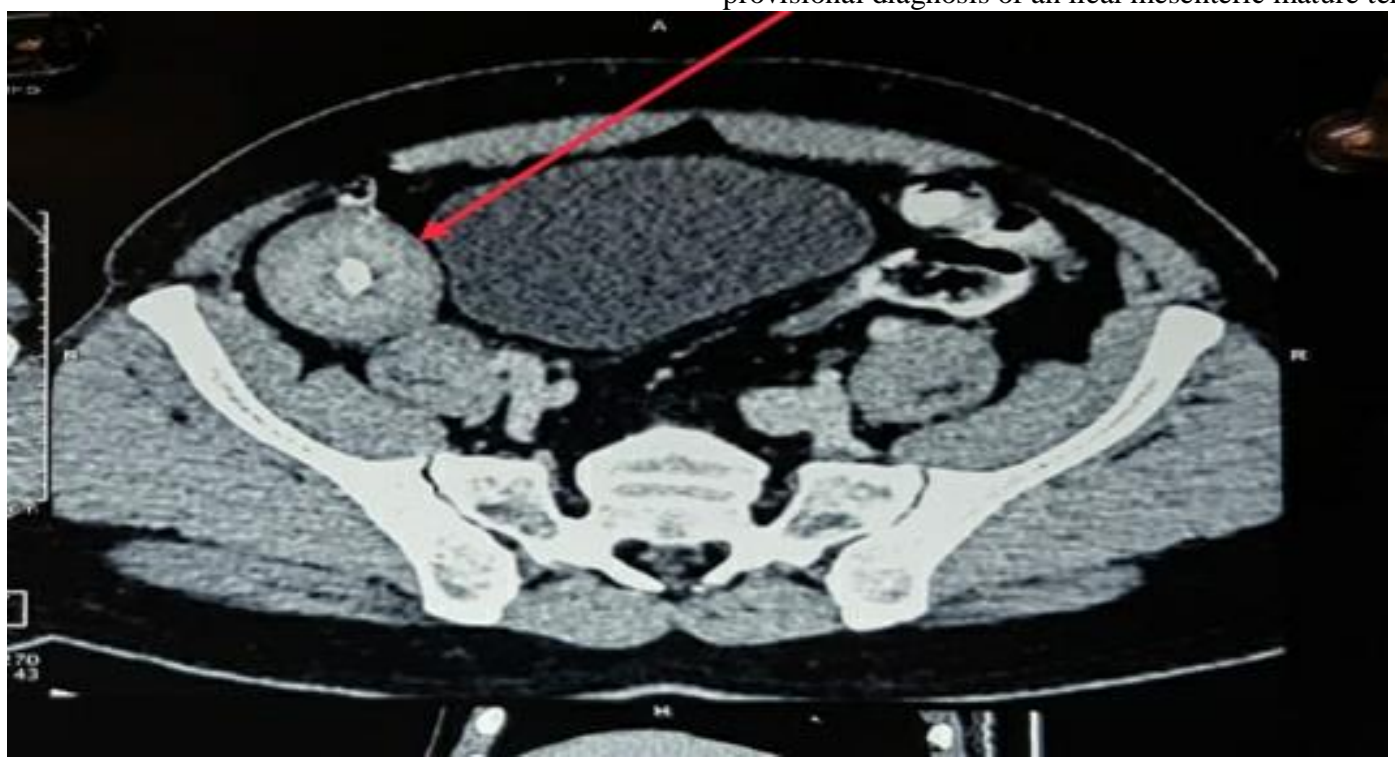

Figure 1- CT scan of the abdomen showing a peritoneal loose body 
On laparotomic examination, an ovoid, well circumscribed, egg-like, hard, freely mobile structure was found in the abdomen. Rest of the intestine, abdominal and pelvic organs were normal.

Grossly, the pelvic mass was a 4.7 x $4.8 \times 4.9 \mathrm{~cm}$ sized ovoid structure, pearly white in colour, with a hard and glistening surface. Cut surface showed the presence of a central concretion of creamy material surrounded by a calcified rim of tissue.
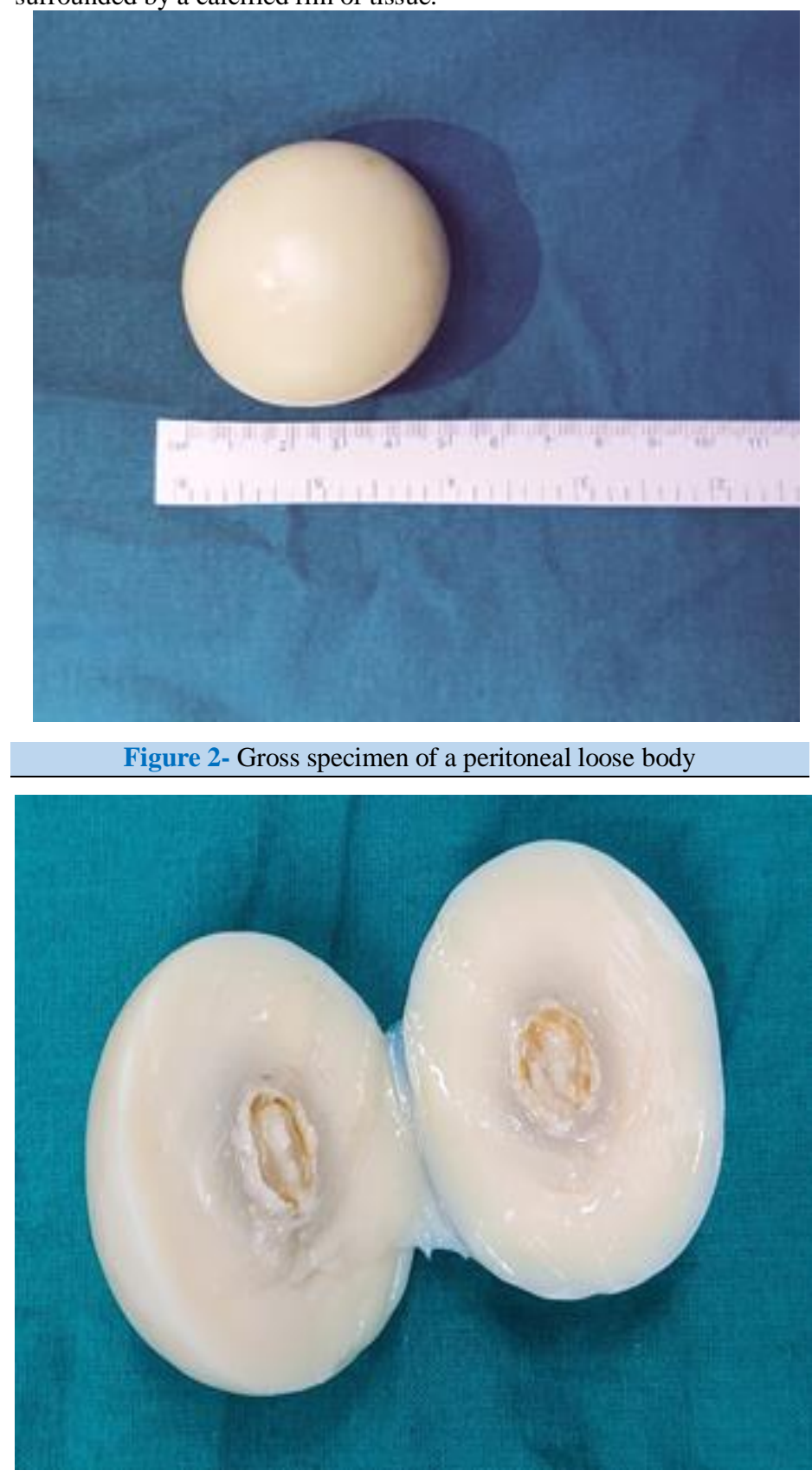

Figure 3- Cut section of a peritoneal loose body

Histopathological report of the lesion mentioned a completely hyalinized, centrally calcified nodule with no viable cells

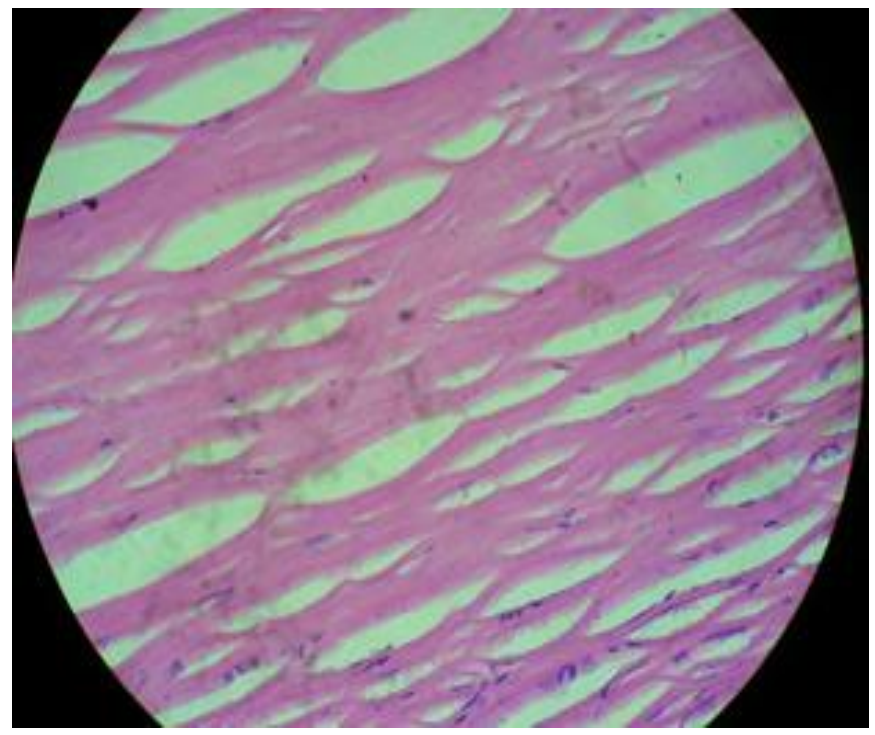

Figure 4- Histopathological slide of a peritoneal loose body

The post-operative course of the patient was unremarkable and patient was discharged on Post-operative day 7. On follow up, the patient was doing well with no further complaints and the wound had healed well.

\section{Discussion}

The etiopathogenesis of a PLB is not very clearly understood. The most commonly accepted theory is that given by Desai et al [1] who gave the theory of appendices epiploicae torsion. According to this theory, an appendix epiploicae having a thin pedicle undergoes torsion and subsequent aseptic necrosis of the fat. This is later followed by saponification and calcification of the fat. Ultimately, the pedicle degenerates and the calcified appendix epiploicae detaches to form a peritoneal loose body. Subsequent multiple peritoneal reactions cause the deposition of serum over this body which later undergoes microcalcification. Thus, the PLB consists of multilamellar, acellular fibrous tissue having a central core of saponified tissue with a calcified rim. In support of this theory, Donald and Kerr [2] demonstrated the formation of peritoneal free bodies in Guinea Pigs by placing peri-pelvic organ fat in the abdominal cavities of these animals. Subsequently, PLBs were observed in the abdomen of these creatures. The clinical presentation of PLBs is dependent mainly on ztheir location and their size. There is no particular predilection for the location of PLBs, although most of them are found freely floating in the abdomen and hence located in the dependent part of the body. Most PLBs remain small and asymptomatic and do not warrant surgical intervention. Large PLBs sized $5 \mathrm{~cm}$ can cause compression symptoms in the abdomen that can result in acute/subacute intestinal obstruction, urinary obstruction, urinary tract infection, abdominal fullness [3] etc. and warrant surgical intervention. The diagnosis of a peritoneal loose body can often be tricky due to this being a very rare finding. While it will be difficult to correctly diagnose a PLB on a plain radiograph of the erect abdomen, a CT scan of the abdomen will show a well defined oval body with minimal to no obliteration of surrounding fat planes and a calcified core with surrounding soft tissue. The differentials of such findings may include benign lesions like foreign body granulomas, gallstones, spontaneously detached ovaries, calcified lymph nodes, calcified uterine fibroids, enlarged mesenteric lymph nodes, fecoliths, echinococcal cysts, abdominal tuberculosis, as well as malignant lesions like mature teratoma, metastatic ovarian cancer lesions, desmoid tumours, urinary tract tumours, calcifying fibrous pseudotumours etc. [3] 


\section{References}

1. Desai HP, Tripodi J, Gold BM, Burakoff R. (1993) Infarction of an epiploic appendage. Review of the literature. J Clin Gastroenterol; 16(4): 323-325.
2. Donald KJ, Kerr JF. (1968) Peritoneal loose bodies. Aust NZ J Surg; 37(4): 403-6.

3. Kim H-S, Sung J-Y, Park WS, Kim YW. (2013) A Giant Peritoneal Loose Body. Korean J Pathol; 47(4): 378-382.
This work is licensed under Creative Commons Attribution 4.0 License

To Submit Your Article Click Here: Submit Manuscript

DOI: $10.31579 / 2690-1897 / 055$
Ready to submit your research? Choose Auctores and benefit from:

* fast, convenient online submission

* rigorous peer review by experienced research in your field

* rapid publication on acceptance

* authors retain copyrights

* unique DOI for all articles

* immediate, unrestricted online access

At Auctores, research is always in progress.

Learn more www.auctoresonline.org/journals/journal-of-surgical-casereports-and-images 